\title{
Relationship between Birth Weight, Placental Weight and Apgar score in Dosso, Niger Republic
}

\author{
Barnabas Danborno, ${ }^{1}$ Sidikou Abbas, ${ }^{1}$ Angela Member Danborno, ${ }^{2}$ Monday Nwankwo ${ }^{3}$ \\ 'Department of Human Anatomy, Faculty of Basic Medical Sciences, College of Medical Sciences Ahmadu Bello University, Zaria \\ ${ }^{2}$ Department of Physiology, Faculty of Basic Medical Sciences, College of Medicine and Health Sciences, Bingham University, Karu-Nigeria \\ ${ }^{3}$ Department of Human Anatomy, Faculty of Medical Sciences, Federal University Lafia-Nigeria
}

Disclose and conflicts of interest: none to be declared by all authors

\section{ABSTRACT}

Introduction: Birth weight (BW) is a significant indicator of neonates' health at birth and reflects the mother's reproductive health. Placental weight (PW) and its ratio to BW has been associated with some adult-onset of diseases. In the present study, the relationship between BW, PW and Apgar score (AS) of babies born between 1996-2006 in Dosso Regional Hospital was analyzed.

Methods: Dataset of 10,540 maternity records, which include BW, PW and AS were collected from the maternity unit of the Dosso Regional Hospital. The data were analyzed using appropriate statistical tests to investigate sexual dimorphism in newborn parameters between males and females and evaluate the relationship between BW, PW and Apgar score.

Results: BW and PW were sexually dimorphic with male neonates having significantly heavier weights than female. Though females have significantly higher AS. BW was significantly associated with PW (male: $r=0.37, P<0.001$; female: $r=0.0 .40, P$ $<0.001$ ) and 5-minute AS (male: $r=0.12, P<0.01$; female: $r=0.15, P<0.01$ ). PW is also significantly associated with AS (male: $r=$ $0.08, P<0.01$; female: $r=0.10, P<0.01)$.

Conclusion: BW was significantly and positively associated with PW and AS.

Keywords: Birth weight, placental weight, APGAR Score, Niger Republic

\section{Introduction}

It is considered that birth weight (BW) is a reliable marker of infant health at birth, and marks the mother's reproductive health and welfare. It is one of the strongest predictors of infant mortality risk., ${ }^{1,2,3}$ During the mid-1990s, the mean BW for singleton black infants born in the U.S. was 3132 grams, about 277 grams less than the mean BW of 3,409 grams for whites, ${ }^{4}$ and 294 grams higher (3,115 grams) than those of infants born between 2005 to 2009 in Bauchi State, Nigeria. ${ }^{5}$ It has been estimated that black infants are more than twice as likely as white infants to be born at BWs below 2,500 grams, ${ }^{5}$ in which case the risk of infant mortality is 24 times greater than for infants with BWs above 2,500 grams, and three times more likely than whites to be born at BWs less than 1,500 grams, in which case the risk of infant mortality is 100 times greater. $^{3}$

For many years, the impact of BW is considered to extend well beyond infancy. Fetal undernutrition, for which low BW is an indicator, may permanently program the body, a phenomenon known as fetal origin hypothesis. ${ }^{6}$ For instance, this may take the form of reduction in cell number in specific organs, altering the distribution of cell types, or affecting metabolic processes. The programmed changes have been implicated with a number of chronic disease outcomes later in life such as cardiovascular disease, ${ }^{7}$ impaired cognitive function, ${ }^{8,9}$ diabetes mellitus ${ }^{10}$ and hypertension. ${ }^{11}$

Placenta is very important because it is responsible for gaseous exchange, exchange of nutrients and electrolytes, detoxification of certain drugs, manufacture of hormones (such as progesterone, estradiol, estrogen, human chorionic gonadotropin and somatomammotropin) and transmission of maternal antibodies. ${ }^{12}$ Placenta and chorion jointly formed the fetal-maternal interface, derived from the trophoblast that separates from the inner cell mass and envelops the cellular precursors of the embryo.

Ishikawa et al. ${ }^{13}$ has reported a close association between fetal and PWs in humans, pigs, rabbits and rodents and also the effects of abnormal placental growth on fetal development particularly in humans and mice. Lower placental growth rates are good predictors of intrauterine growth retardation (IUGR) and low BWs. ${ }^{14}$ The placentas of low BW babies are often small or poorly attached and might have undergone degenerative changes that gradually reduce nourishment and oxygen supply to the fetus.

Diminutive placental tissue function results in decreased perfusion area between the mother and fetus leading to impaired exchange of oxygen and 
nutrients from the mother to the fetus. The result from this study therefore showed that fetal growth is limited by the size of and role of the placenta. Report by Heinonen and colleagues ${ }^{15}$ revealed that placentas in small-for-gestational age (small for dates) babies were $24 \%$ smaller than those from appropriate-forgestational age babies. This suggests direct linear association between fetal growth and placental weight (PW). The findings of Kosinka ${ }^{16}$ is consistent with previous reports..$^{15-17,18,19} \mathrm{~A}$ general examination of the placenta after delivery can give an insight about the in utero environment before delivery. Small placentas can be associated with trisomies while large placentas can be associated with maternal diabetes

The National Center for Health Statistics describes Apgar score (AS) as a "predictor of the infant's chances of surviving the first year of life" and a "summary measure of the infant's condition". ${ }^{20}$ The AS ranges from 0 to 10 (10 being the perfect score) and is computed from five different tests of newborn health made at one and five minutes after birth. ${ }^{21}$ At birth, the doctor evaluates each of the five factors on a rating of 0,1 , or 2 for each factor. The five health factors are heart rate, respiratory effort, reflex irritability, color and muscle tone, the baby's score for each of the five factors are summed up to compute $\mathrm{AS}^{22}$ Because infants weighing 1500 grams have higher chance of survival, AS may provide additional underpinning information on infant health at birth. Though this measure is highly significantly associated with infant mortality, there is significant variability in ASs among newborns who made it through their first year of life, and this variability is highly significantly correlated with different measures of health at birth. ${ }^{23}$

This study was designed with the aim of empirically investigating the relationship between BW, PW and AS of infants born in Dosso State, Niger Republic retrospectively.

\section{Methodology}

\section{Dataset}

The present study is based on a dataset of 10,540 singleton births which took place at the Regional Hospital of Dosso, Niger Republic between 1996 and 2006. Data were obtained from the maternity register. The parameters studied include BW, PW, AS and sex of babies.

\section{Newborn Parameters}

The BW and sex of newborn were obtained from the maternity register of the regional hospital, for the years 1996 to 2006. The BW was classified according to the recommendations of the world health organization; ${ }^{24}$ low BW was defined as $<2,500$ grams and normal BW as 2,500 to 4,000 grams. Approval for the study was received from the Health Research Ethics Committee, Ahmadu Bello University Teaching Hospital, Zaria,
Nigeria and approval of the regional hospital authority in Dosso.

\section{Statistical analyses}

Data was expressed as mean \pm standard deviation. Student's t-test was used to test for the difference in the means of the BWs, PW and AS in male and female newborns. Correlation analysis was used to examine the relationship between BW, PW, and AS. Multiple linear regression was used to generate predictive equations for the respective variables. Two-tailed $P<0.05$ was accepted as statistically significant. SigmaStat 3.5 (Systat Inc., San Rafael, CA) for Windows was used for the statistical analyses.

\section{Results}

The mean BW, mean 5-minute AS, and mean PW for males and females born between 1996-2006 are shown in Figures 1 and 2. BW, PW and 5-minute AS of male and female babies were significantly $(\mathrm{P}<0.01)$ different. Male babies are significantly heavier $(t=7.95, P<0.001)$ and have significantly heavier PW $(t=4.35, \mathrm{P}<0.001)$. However, female babies have significantly 5 -minute AS than male babies $(t=3.01, P=0.003)$. Still on the Figure 1, BW is approximately five times PW for both male and female babies. Table 1 presents the correlation coefficients between BW and PW and 5-minute AS for male and female newborns. The results showed that all the variables are statistically significant. For both male and female newborns, BW was highly positively correlated with PW (male, $r=0.37, \mathrm{P}<0.001$; female, $r=$ 0.40, $\mathrm{P}<0.001)$. Compared to the correlation between birthweight and PW, BW showed slightly lower significant $(P<0.01)$ linear association with 5 -minute AS while 5-minute AS showed least linear relationship with $\mathrm{PW}(\mathrm{P}<0.01)$. Table 2 provides predictive equations for body weight, PW and 5-minute AS for both sex.

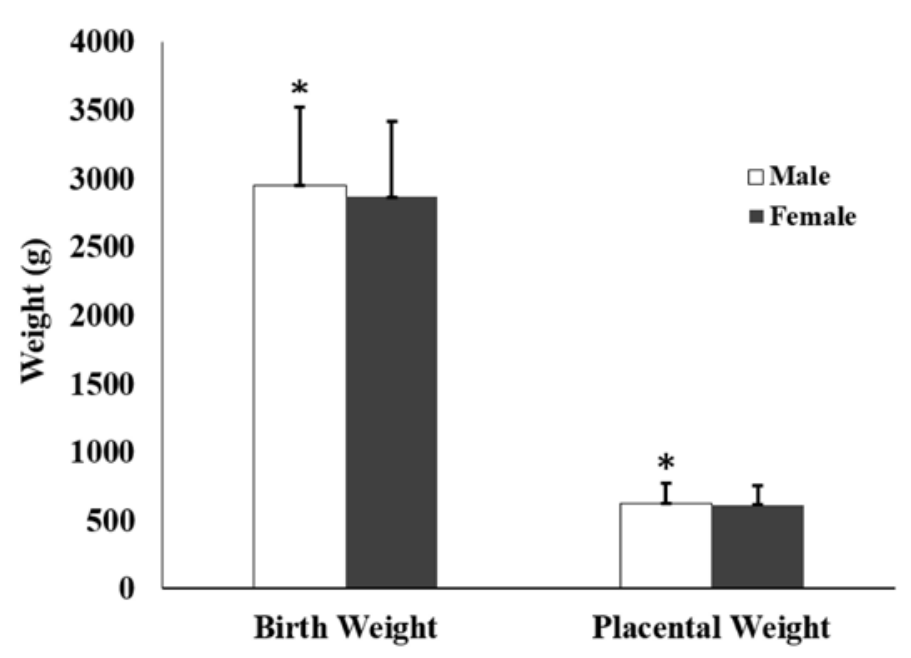

Figure 1. Comparisons of birth and placental weights for male and female newborns. Both birth weight and placental showed significant difference between males and females neonates ${ }^{*} P<0.001$. 


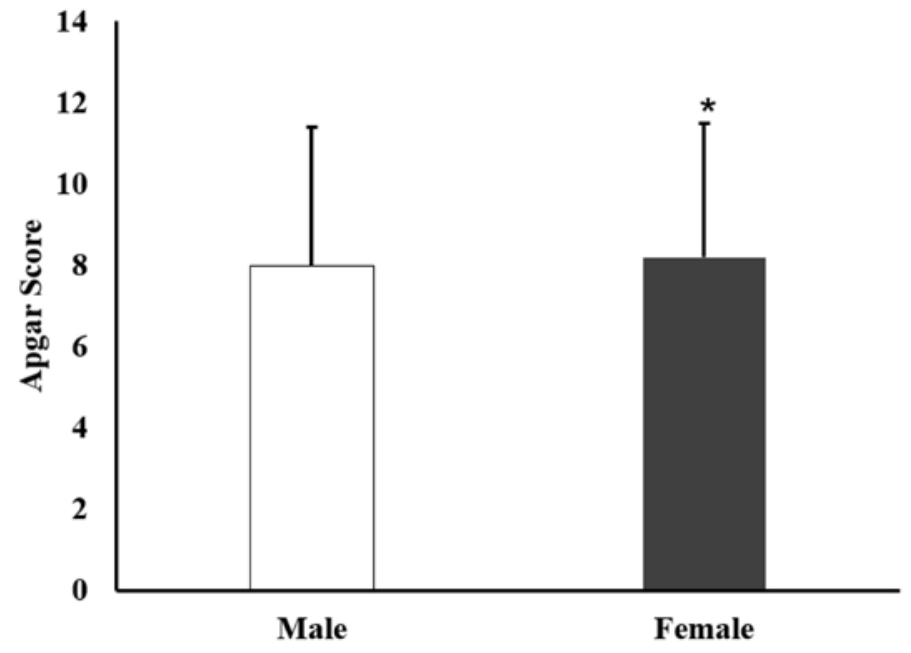

Figure 2. Comparison of 5-minute Apgar score for male and female infants. Female neonates showed significantly higher Apgar score ${ }^{*} P<0.001$.

Table 1: Pearson coefficient of correlation matrix

\begin{tabular}{l|c|c|c}
\hline \multicolumn{2}{c|}{ Apgar score } & Birth weight & $\begin{array}{c}\text { Placental } \\
\text { weight }\end{array}$ \\
\hline Males (n = 5733) & - & $0.12^{*}$ & $0.08^{*}$ \\
\hline Apgar score & - & - & $0.37^{* *}$ \\
\hline Birth weight & & & - \\
\hline Placental weight & & & \\
\hline
\end{tabular}

Females $(n=4807)$

\begin{tabular}{l|c|c|c}
\hline Apgar score & - & $0.15^{*}$ & $0.10^{*}$ \\
\hline Birth weight & & - & $0.40^{* *}$ \\
\hline Placental weight & & & - \\
\hline${ }^{*} P<0.01{ }^{* *} P<0.0$ &
\end{tabular}

lower than that of babies born in Canada $(3,221 \text { grams })^{30}$ and Norway (3,244 grams). ${ }^{31}$ This variation may be due to methodological variabilities and genetics.

Compared to the BW of female, male neonates are significantly heavier and have heavier placenta than their female counterparts. Previous studies have established sexual dimorphism in BW from a study conducted in Zaria, Nigeria. ${ }^{32}$ The heavier PW among male neonates might explain the higher BW. Heavier placenta has higher surface area to volume. This in turn increases the rate of gaseous exchange, exchange of nutrients and electrolytes between the mother and fetus. The difference in BW may also be attributed to physiologic differences in body composition. The body composition of the male neonates is expressed by muscle mass while that of female neonates by fat stores. Assessment of the nutritional status is recommended to evaluate the variabilities in BW and pathophysiological factors that might be responsible for low BW. There is, however, an important caveat to these kinds of conclusions. The heavier BW in male neonates may partially reflect the influence of unobserved variables not just higher surface area to volume of placenta or body composition. For example, it is a logical possibility that the genetic inheritance of some neonates predisposed them to inherent disadvantage to attain normal BW among the female neonates. More generally, there is need for future studies to control for PW and genetic while evaluating the cause of variation in BW based on sex.

Nevertheless, placental volume and the rate of placental growth may influence fetal size. These effects are evident in the first half of pregnancy and appear

Table 2. Prediction equations for estimating average value of 5-minute Apgar score, birth and placental weight

\begin{tabular}{|c|c|c|c|c|c|c|c|}
\hline Sex & Dependent variables & Predictive Equations & SEE & $\mathbf{R}$ & $\mathbf{R}^{2}$ & $\mathbf{t}$ & $\mathbf{P}$ \\
\hline \multirow{3}{*}{$\begin{array}{l}\text { Females } \\
(n=4807)\end{array}$} & 5-minute Apgar score & $=5.312+(0.0001 \times \mathrm{BW})+(0.00108 \times \mathrm{PW})$ & 3.261 & 0.15 & 0.02 & 19.16 & $<0.001$ \\
\hline & Birth weight & $=1769.05+(1.543 \times \mathrm{PW})+(18.296 \times \mathrm{AP})$ & 502.349 & 0.41 & 0.17 & 48.91 & $<0.001$ \\
\hline & Placental weight & $=317.900+(1.641 \times \mathrm{AP})+(0.0987 \times \mathrm{BW})$ & 127.044 & 0.40 & 0.16 & 31.10 & $<0.001$ \\
\hline \multirow{3}{*}{$\begin{array}{l}\text { Males } \\
(n=5733)\end{array}$} & 5-minute Apgar score & $=5.577+(0.00633 \times \mathrm{BW})+(0.00083 \times \mathrm{PW})$ & 3.398 & 0.12 & 0.02 & 21.31 & $<0.001$ \\
\hline & Birth weight & $=1965.95+(15.134 \times$ AP $)+(1.385 \times P W)$ & 525.450 & 0.38 & 0.15 & 59.51 & $<0.001$ \\
\hline & Placental weight & $=329.269+(1.441 \times \mathrm{AP})+(1.385 \times \mathrm{PW})$ & 138.861 & 0.37 & 0.14 & 32.22 & $<0.001$ \\
\hline
\end{tabular}

$\mathrm{BW}=$ birth weight $\mathrm{AP}=5$-minute $\mathrm{Apgar}$ score $\mathrm{PW}=$ placental weight $\mathrm{SEE}=$ standard error of estimate

\section{Discussion}

It is a known fact that BW is in general an important predictor of baby's health and a direct target of obstetric policy. It is also a reflection of maternal wellbeing. The average placental and BW of babies born in Dosso were similar to that of babies born in Southwest Nigeria. ${ }^{26}$ Result from the present study also showed that BW of babies born in Dosso (3,115 grams) is similar to that of babies born in United States $(3,170 \text { grams })^{27}$ and the UK $(3,072-3,129)$ grams, ${ }^{28}$ but higher than that of babies born in South Asia (3,032 grams) ${ }^{29}$ though to be mediated through maternal weight and weight gain. ${ }^{33}$ An excessively large placenta, or a large ratio of PW to BW is taken to be a sign of fetal malnutrition. ${ }^{34,35,36}$ A large placenta has a pathophysiological significance, and the link may be that a large placenta is a sign of maternal anemia and hence an indicator of suboptimal maternal nutrition. ${ }^{34}$

The 5-minute AS for both male and female neonates are well-above average. Both BW and AS are reflection of baby's health and condition at birth. Though surprisingly, 5-minute AS of female neonates is 
significantly higher than that of male neonates (despite having significantly higher birth and PWs). The most plausible explanation for this is that either all or some of the five factors being evaluated while computing AS act independent of birth and PWs. However, AS showed significant linear association with birth and PWs. Another probable explanation for lower AS observed among male neonates is that BW strongly influenced the risk of low 5-minute AS, with a five-fold risk for the smallest and a six-fold risk for the heaviest infants. Gestational age at birth also influenced 5-minute AS.

Low 5-minute AS is strongly influence by BW and gestational age. A low BW is known to be a risk factor for fetal compromise, being a typical finding in cases of chronic placental insufficiency. ${ }^{37}$ The mean 5-minute AS is lower in these newborns because of high incidence of hypertension in women in this area of Niger Republic.

Also, birth and PWs are significantly correlated in our study. The strong correlation between placental and BWs as observed in the present study is consistent with previous. ${ }^{18,25,33}$ Data gathered from Medical Birth Registry in Norway of babies born between 1 January 1999 to December 2002 showed strong positive correlation between $\mathrm{BW}$ and $\mathrm{PW},{ }^{38}$ results from more recent studies also showed significant association..$^{39,40,41}$

\section{Conclusion}

There is highly significant association between BW, PW and 5-minute AS. There are significant differences between mean BW, mean PW, mean 5-minute AS in males and females newborns. The mean 5-minute AS values of newborns were significantly lower for males than females.

\section{Acknowledgements}

We gratefully acknowledged the assistance giving to us by the management of the Regional Hospital in Dosso, Niger Republic.

\section{References}

1. Institute of Medicine. Preventing low birth weight. Washington, D.C. National Academy Press 1985.

2. Cramer JC. Social factors and infant mortality: Identifying high-risk groups and proximate causes. Demography 1987; 24: 299-322.

3. Mathews TJ, MacDorman MF. and Menacker Fay. Infant mortality statistics from the 1999 period linked birth/infant death data set, National Vital Statistics Reports, Vol. 50, No. 4. Hyattsville, MD: National Center for Health Statistics.

4. Martin JA, MacDorman MF, Mathews TJ. Triplet births: Trends and outcomes, 1971-94, Vital and Health Statistics, Ser. 21, No. 55. Hyattsville, MD: National Center for Health Statistics.

5. Umar A, Danborno B, Murtala MJ and Ismaila A. Retrospective study of maternal age and birth weight in Abubakar Tafawa Balewa University Teaching Hospital (ATBUTH) Bauchi State, Nigeria. Asian J. Med. Pharm. Res. 2014; 4 (1): 01-04.

6. Barker DJP. Mothers, babies, and disease in later life. Second edition. London: BMJ 1998; Publishing Group.

7. Rich-Edwards JW, Stampfer MJ, Manson JE, et al. Birth weight and the risk of cardiovascular disease in a cohort of women followed up since 1976; Bri Med J

8. Sorensen, H T, Svend S, Jorn Olsen, Kenneth J. Rothman, Matthew W. Gillman, and Peer Fischer. Birth weight and cognitive function in young adult life: Historical cohort study. British Med J 1997; 315: 401403.

9. Richards M, Hardy R, Kuh, and Michael E. J. Wadsworth. Birth weight and cognitive function in the British 1946 birth cohort: Longitudinal population-based study. Bri Med J 2001; 322: 199-203.

10. Barker DJP, Hales CN, Fall CHD, Osmond C, Phipps K, and Clark PMS. Type 2 (non-insulin-dependent) diabetes mellitus, hypertension and hyperlipidaemia (Syndrome X): Relation to reduced fetal growth. Diabetologia 1993; 36: 62-67.

11. Law, C.M., M. de Swiet, C. Osmond, et al. Initiation of hypertension in utero and its amplification throughout life. Bri Med J 1993; 306: 24-27.

12. Chucr TM, Monteiro JM, Lima AR, Salvadori ML, Kfoury Jr, JR, Miglino MA. Review of immune transfer by the placenta. J Reprod Immunol 2010; 87:1-2:14-20.

13. Ishikawa H, Seki R, Yokonishi S, Yamauchi T and Yokoyama K. Relationship between fetal weight, placental growth and litter size in mice from mid- to late-gestation. Reprod Toxicol. 2006; 21 267-270. 14. Bleker OP, Buimer M, van der Post JAM, van der Veen FT (G.J.) Kloosterman: On Intrauterine Growth. The significance of Prenatal
Care. Studies on birth weight, placental weight and placental index. Placenta 2006; 27:1052e1054.

15. Heinonen S, Taipale P, Saarikoski S. Weights of placentae from small-for-ges-tational age infants revisited. Placenta 2001; 22(5):399404.

16. Kosińska M, Stoińska B, Gadzinowski J. Catch-up growth among low birth weight infants. Anthropol Rev 2004; 67:87-95.

17. Jaya DS, Kumar NS, Bai LS. Anthropo-metric indices, cord length and placental weight in newborns. Indian Pediatr. 1995; 32(11):1183-8. 18. Salafia CM, Zhang J, Charles AK, Bresnahan M, Shrout P, Sun W, Maas EM. Placental characteristics and birth weight. Paediatr Perinat Epidemiol 2008; 22(3):229-39.

19. Roland MC, Friis CM, Voldner N, Godang K, Bollerslev J, Haugen G, Henriksen T. Fetal growth versus birthweight: the role of placenta versus other determi-nnants. PLoS One 2012; 7(6): e39324.

20. National Center for Health Statistics. Vital Statistics of the United States: Natality, 1990. Hyattsville, MD: National Center for Health Statistics.

21. Jonnett RJ, Wardford HS, Kreinnick C, Waterkotte GW. The Apgar index: a statistical tool. Am J Obstet Gynecol 1981; 140:2016-212.

22. O'Donnel CPF, Kamlin OF, Davis PG, Carlin JB. and Morley CJ. Interobsever variability of the 5minute 5-minute AS. J Pediatr 2006; 149:486-9.

23. Douglas Almond, Kenneth Y. Chay, David S. Lee. The costs of low birth weight. The Quarterly J Econ. 2005; 2:1031-1083

24. WHO (1980). Division of family planning. The incidence of low birth weight. A critical review of available information. Geneva: World Health Organization Status Quarterly 33:197-224.

25. Sitti P, Yasmin S, Razak TA. (2015). The correlation between placental weight and birth weight. Int Proc Chem Biol Environ Eng, Vol. 86 (2015).

26. Adebami OJ, Owa JA, Oyedeji GA. Factor associated with placenta weight and PW/birth weight percent (placental ratio) among mothers in Ilesa, Southwestern Nigeria. Int J Trop Med. 2007; 2 (2):68-73.

27. Alexander GR, Wingate MS, Mor J, Boulet S. Birth outcomes of Asian-Indian-Americans. Int J Gynaecol Obstet 2007; 97:215-220.

28. Leon DA, Moser KA. Low BW persists in South Asian babies born in England and Wales regardless of maternal country of birth: slow pace of acculturation, physiological constraint or both? analysis of routine data. J Epidemiol Commun Health 2012; 66:544-551.

29.de Wilde J.A. van Buuren S. Middelkoop BJC. Trends in birth weight and the prevalence of low BW and small-for-gestational-age in 
Surinamese South Asian babies since 1974: cross-sectional study of three birth cohorts. BMC Public Health 2013; 13:931.

30. Ray JG, Jiang D, Sgro M, Shah R, Singh G, Mamdani MM. Thresholds for small for gestational age among newborns of East Asian and South Asian ancestry. J Obstet Gynaecol Can 2009; 31:322-330.

31. Vangen S, Stoltenberg C, Skjaerven R, Magnus P, Harris JR, StrayPedersen B: The heavier the better? Birth weight and perinatal mortality in different ethnic groups. Int J Epidemiol 2002; 31:654-660. 32. Danborno B, Afegbua A. Ethnic differences in birth weight and cesarean deliveries in Zaria. J Experiment Clin Anat. 2006; 5:21-24.

33. Thame M, Osmond C, Bennett F, et al. Fetal growth is directly related to maternal anthropometry and placental volume. Eur J Clin Nutr 2004; 58 (6):894-900.

34. Wigglesworth JS. Aetiology of fetal undergrowth. In: Sharp F, Fraser RB, Milner RDG. Fetal growth. London: Springer-Verlag, 1989:185-95.

35. Chilswick ML. Intrauterine growth retardation. BMJ 1985; 291:845-8. 36. Bonds DR, Gabbe SG, Kumar S, Taylor T. Fetal weight placental weight ratio and perinatal outcome. Ann Hum Biol. 1990; 17; 1-6. 37. Golan A, Lin G, Evron S, Arieli S, Niv D, David MP. Oligohydramnios: maternal complication and fetal outcome in 145 cases. Gynecol Obstet Invest. 1994; 37:91-5.

38. Thompson JM, Irgens LM, Skjaerven R, Rasmussen S. Placental weight percentile curves for singleton deliveries. BJOG 2007, 114 (6):715-20.

39. Asgharnia M, Esmailpour N, Poorghorban M and Atrkar-Roshan Z. Placental weight and its association with maternal and neonatal characteristics. Acta Med Iran. 2008; 46 (6):467-72.

40. Risnes KR, Romundstad PR, Nilsen TIL, Eskild A, Vatten LJ. Placental weight relative to birth weight and long-term cardiovascular mortality: findings from a cohort of 31.307 men and women. Am J Epidemiol. 2009; 170 (5): 622-31.

41. Alwasel SH, Abotalib Z, Aljarallah JS, Osmond C, Alkharaz SM, Lahaska IM. Changes in placental size during Ramadan. Placenta, 2010; 31(7): 607-10.
Received: November 10, 2018

Accepted: May 9, 2019
Corresponding author

Barnabas Danborno

sbdanborno@yahoo.com 